\title{
Reinforced acid-pretreatment of Triarrhena lutarioriparia to accelerate its enzymatic hydrolysis
}

\author{
Xue Tao ${ }^{a}$, Juan Li ${ }^{a}$, Panyue Zhang ${ }^{a, *}$, Mohammad Nabi ${ }^{a}$, Shuguang Jin ${ }^{b}$, \\ Fan $\mathrm{Li}^{a}$, Siqi Wang ${ }^{a}$, Junpei Ye ${ }^{a}$ \\ a College of Environmental Science and Engineering, Beijing Forestry University, Beijing 100083, China \\ ${ }^{\mathrm{b}}$ Research Center for Eco-Environmental Sciences, Chinese Academy of Sciences, Beijing 100085, China
}

\section{A R T I C L E I N F O}

Article history:

Received 20 January 2017

Received in revised form

11 March 2017

Accepted 18 April 2017

Available online 14 May 2017

Keywords:

Triarrhena lutarioriparia

Acid pretreatment

Ultrasound

Microwave

Enzymatic hydrolysis

\begin{abstract}
A B S T R A C T
In this study, physical method reinforced chemical pretreatments of Triarrhena lutarioriparia (TL) were compared to explore the higher reducing sugar yield in subsequent enzymatic hydrolysis. Four different pretreatments, namely hydrothermal pretreatment (HTP), dilute acid pretreatment ( $\mathrm{HCl}-\mathrm{P})$, ultrasound assisted acid pretreatment $(\mathrm{HCl}+\mathrm{U})$ and $\mathrm{mi}-$ crowave assisted acid pretreatment $(\mathrm{HCl}+\mathrm{M})$ were conducted on TL. The structural features of TL after different pretreatments were investigated by Scanning electron microscopy (SEM), X-ray powder diffraction (XRD) and Fourier transformed infrared (FT-IR) techniques. The fractal-like theory was introduced to study the enzymatic hydrolysis kinetics of TL. Results showed that the reducing sugar yield of HCl-P reached $100.14 \mathrm{mg} / \mathrm{g}$, showing 1.34 times higher than that of the raw. Due to the hemicellulose and lignin removal and lignocellulosic structure destruction, ultrasound and microwave irradiation strengthened the HCl-P, leading to a great enhancement of enzymatic hydrolysis of TL, especially the microwave irradiation. Moreover, the fractal-like theory was confirmed to be satisfactory for studying the enzymatic hydrolysis kinetics of lignocellulosic biomass.
\end{abstract}

๑ 2017 Hydrogen Energy Publications LLC. Published by Elsevier Ltd. All rights reserved.

\section{Introduction}

Over the past few decades, an increase in excessive and unsustainable fossil fuel use has led to serious environmental problems, such as large amounts of carbon dioxide emissions and global warming [1]. In order to counteract this serious situation, production of environmental-friendly energy including renewable lignocellulosic biomass has a high priority to ensure global energy security and environmental protection. Fortunately, in more recent years, more attention has been focused on biofuel production from lignocellulosic biomass [2-4]. T. lutarioriparia (TL) is a species of perennial herb with a well-developed rhizome, adapts well to warm and humid environments, and does not compete for land with food with a high biomass productivity more than $22.5 \mathrm{t} /\left(\mathrm{a}^{*} \mathrm{ha}\right)$ $[5,6]$. This plant has become a notable source of energy plants, and has a great potential for biofuel production.

The conversion of lignocellulosic biomass to biofuel is currently a topic of great interest around the world. However, this technology is limited by the poor deconstruction and enzymatic hydrolysis. This resistance is mainly caused by the stable chemical structure and components of raw biomass,

\footnotetext{
* Corresponding author. College of Environmental Science and Engineering, Beijing Forestry University, Qinghua East Road 35, Haidian District, Beijing 100083, China. Fax: +86 1062336900.

E-mail addresses: Taoxuegz@163.com (X. Tao), panyue_zhang@bjfu.edu.cn (P. Zhang).
} 
which build a dimensional and irregular layer as a protective network [7]. Inexpensive and efficient pretreatments for biomass conversion are required to break the recalcitrance of lignocellulosic biomass for improving the amount of biomass accessible surface to enzyme, and decreasing the loss of reducing sugar during the pretreatment process [8].

In previous studies, numerous promising pretreatment approaches including chemical, physical, biological, and combined pretreatments have been applied to decrease the recalcitrance and enhance the enzymatic saccharification of lignocelluloses biomass, such as hydrothermal, microwave irradiation, high-pressure homogenization, acid, alkaline and white-rot fungi pretreatment [9-13]. Among these pretreatments, dilute acid pretreatment has received a lot of attention and has a wide range of applications [14,15]. Main objective of dilute acid pretreatment is to solubilize the hemicellulosic fraction from biomass, thus making the biomass more susceptible to enzymatic hydrolysis [16,17]. Some studies reported that more than $80 \%$ hemicellulose could be solubilized from the lignocellulosic feedstock by dilute acid pretreatment, which facilitated the subsequent enzymatic hydrolysis of biomass [18].

Microwave heating has been proved an effective and promising method to pretreat the lignocellulosic biomass, increasing reaction temperature and disrupting biomass structure for biofuel production [19]. Ultrasound pretreatment is used to improve chemical reactions and industrial processes by shearing action, cavitation effect and reactive radical oxidation $[20,21]$. Various pretreatments have different effects on lignocellulosic biomass. Furthermore, combined pretreatments (such as microwave+alkali and microwave + acid) have an obvious effect on the enzymatic hydrolysis of lignocellulosic biomass [22,23]. Singh et al. reported that a maximum reducing sugar reached $1334.79 \mu \mathrm{g} / \mathrm{ml}$ after microwave assisted $\mathrm{NaOH}$ pretreatment [24]. However, the effect of assisted physical methods on reinforcing dilute acid pretreatment of TL for enzymatic hydrolysis is rarely reported.

Therefore, the objective of this study was to compare the effectiveness of reinforcing dilute acid pretreatment by various physical approaches for enzymatic hydrolysis of TL, and analyze the composition and structure change of TL after pretreatments by scanning electron microscopy (SEM), X-ray powder diffraction (XRD) and Fourier transformed infrared (FT-IR) techniques. Meanwhile, the fractal-like theory was introduced to estimate the enzymatic hydrolysis kinetics of TL after different pretreatments.

\section{Materials and methods}

\section{Materials}

TL was collected from Beijing, China. The air-dried sample was milled to pass 20 mesh size by a laboratory mill (DF-25S, Dade, China), then stored in plastic bags at room temperature. All chemicals were of analytical grade and purchased from Beijing Chemical Industry Group Co., China. The commercial enzyme was purchased from Hunan province, China, which was generated by Trichoderma reesei.

\section{Methods}

Hydrothermal and acid pretreatments

For hydrothermal pretreatment (HTP) and dilute hydrochloric acid pretreatment (HCl-P), $10 \mathrm{~g}$ dried TL was immersed in $100 \mathrm{ml}$ of distilled water and $\mathrm{HCl}$ solution of $10 \%(\mathrm{w} / \mathrm{v})$ at $120^{\circ} \mathrm{C}$ for $1 \mathrm{~h}$ with agitation in a round-bottom flask, respectively. After the pretreatment, the solid fraction was separated by filtering, and then washed with tap water until a neutral $\mathrm{pH}$. The obtained solid fraction was dried at $65^{\circ} \mathrm{C}$ and then used as substrate for the subsequent enzymatic hydrolysis.

Microwave assisted acid pretreatment $(\mathrm{HCl}+\mathrm{M})$

Microwave irradiation was carried out in a domestic microwave oven (Samsung, S7A73). After $\mathrm{HCl}$ pretreatment, the flask containing substrate mixture was placed into the microwave reactor. The microwave treatment time lasted $6 \mathrm{~min}$ with a power of $400 \mathrm{~W}$. After that, the flask was taken out from the microwave oven, and the solid fraction was separated and dried according to Section "Hydrothermal and acid pretreatments".

\section{Ultrasound assisted acid pretreatment $(\mathrm{HCl}+\mathrm{U})$}

Ultrasound was generated by a HD2070 Sonopuls Bandelin Ultrasonic Homogenizer device, equipped with MS 73 titanium microtip probe, working with an operating frequency of $20 \mathrm{kHz}$. Ultrasonication was performed with an output power of $200 \mathrm{~W}$ and an exposure time of $30 \mathrm{~min}$. After ultrasonication, the solid fraction was also separated and dried according to Section "Hydrothermal and acid pretreatments".

\section{Enzymatic hydrolysis}

Enzymatic hydrolysis was carried out with a solid loading of $2.5 \%(\mathrm{w} / \mathrm{v})$ at $\mathrm{pH} 4.8$, a temperature of $50{ }^{\circ} \mathrm{C}$ and a rotation speed of $150 \mathrm{r} / \mathrm{min}$ for $72 \mathrm{~h}$ in $250 \mathrm{ml}$ flasks. The enzymeloading was $30 \mathrm{FPU} / \mathrm{g}$ biomass. The reaction mixture was filtered and the liquid was used to analyze the reducing sugar production.

\section{Fractal-like kinetics model}

The fractal-like kinetics model can describe the reactions of materials that are prepared as fractals. This model supposes that the reducing sugar yield consists of several components to form a single combined effect on enzymatic hydrolysis. The reactions fit the fractal-like kinetics model and the reducing sugar yield can be deduced as Eq. (1):

$\mathrm{P}=\frac{\mathrm{S}_{0}}{0.9}\left[1-\exp \left(-\frac{0.9 k}{1-h} \mathrm{t}^{1-h}\right)\right]$

where $\mathrm{P}$ is the concentration of reducing sugar, $\mathrm{S}_{0}$ is the initial concentration of reducing sugar, $\mathrm{h}$ is the fractal dimension describing the substrate fractal, $\mathrm{k}$ is the rate constant presenting the reaction rate between substrates and enzyme, and $t$ is the enzymatic hydrolysis time. The fractal-like kinetics model presents some advantages, such as, effective analytical solution, a good convergence for product formation and a simple equation [25]. 


\section{Analysis methods}

The chemical components of raw and pretreated TL were analyzed by a fiber analyzer (A200i, Ankom, USA). The reducing sugar concentration was measured using the 3,5 dinitrosalicylic acid method.

FT-IR spectra was recorded in the range from 4000 to $400 \mathrm{~cm}^{-1}$ on a Perkin Elmer Spectrophotometer Spectrum Two (USA) fitted with ATR device. The surface morphology and characteristics of the different residual solids were observed by SEM (S-3400N II, Hitachi, Japan) and performed at a beam accelerating voltage of $10 \mathrm{kV}$. All samples were sputter-coated with gold before scanning. XRD of samples was analyzed using an XRD instrument (D8 Advance, Bruker, Germany). The determination was performed with $\mathrm{Ni}$-filtered $\mathrm{Cu} \mathrm{K} \alpha$ radiation $(\lambda=1.54 \AA$ ) at $40 \mathrm{kV}$ and $40 \mathrm{~mA}$. Specimens were scanned at $6 \mathrm{~s} / \mathrm{step}$ from $2 \theta=5^{\circ}-35^{\circ}$ with a step of $0.2^{\circ}$. The sample crystallinity was quantified from XRD data using a crystallinity index by Eq. (2):

CrI $=\frac{I_{002}-I_{\text {amorphous }}}{I_{002}} \times 100 \%$

where $\mathrm{I}_{002}$ is the diffraction intensity of crystalline structure $\left(2 \theta=22.6^{\circ}\right)$, and $I_{\text {amorphous }}$ is the diffraction intensity of amorphous fraction $\left(2 \theta=18.0^{\circ}\right)$ [26].

\section{Results and discussion}

\section{Effect of pretreatment on surface structure of TL}

SEM reveals the superficial physical change of biomass [27]. The structure change after different pretreatment is shown in Fig. 1. The raw TL showed a smooth and compact surface morphology without any traces of erosion, suggesting that the TL was tightly and orderly integrated together. There was no obvious difference compared with the surface of control and that after HTP (Fig. 1B). However, after HCl-P the tight structure of TL disappeared and some small fragments were produced. When microwave or ultrasound was applied the dilute acid pretreatment, the surface structure was further eroded (Fig. 1C and D). Microwave irradiation significantly stripped the outer layer of biomass and altered the organized polymer structure with more porous grooves, and the sample was disrupted more severely than that with other pretreatments. As a result, more holes, cracks and erosion troughs in biomass surface might increase the accessible surface area of cellulose, further improving the subsequent enzymatic hydrolysis. Ultrasound could disrupt the bond between the cellulose and hemicellulose by heating and cavitation effects $[20,28]$. The similar effects were also observed in other publications $[29,30]$.

\section{Effect of pretreatment on chemical composition of TL}

The raw TL consisted of $44.48 \%$ cellulose, $28.38 \%$ hemicellulose and $17.60 \%$ lignin (as shown in Table 1). Compared with the control, no significant change in hemicellulose and lignin content was observed when the TL was pretreated with hydrothermal process. The addition of $\mathrm{HCl}$ had a positive influence on hemicellulose removal. After $\mathrm{HCl}-\mathrm{P}, \mathrm{HCl}+\mathrm{U}$ and $\mathrm{HCl}+\mathrm{M}$, the hemicellulose fraction dramatically decreased to $18.14 \%, 16.74 \%$ and $16.53 \%$, respectively. The combined pretreatments could more effectively solubilize the hemicellulose and lignin than the single HCl-P, keeping the majority of cellulose in the solid residues. As a result, the cellulose could be largely exposed to enzyme and the subsequent enzymatic hydrolysis could be improved. The solid yield after pretreatments is shown in Table 1. After different pretreatments, the solid yield decreased by $65.55 \%-83.50 \%$, which was mainly attributed to the degradation and solubilization of lignin and hemicellulose. Only $65.72 \%$ solid residues were obtained after $\mathrm{HCl}+\mathrm{M}$, which was just because more hemicellulose was dissolved.

Moreover, the chemical and physical pretreatments can change the crystalline region or amorphous region of cellulose. To gain insight into the possible structural features affecting the cellulose hydrolysis, the untreated and
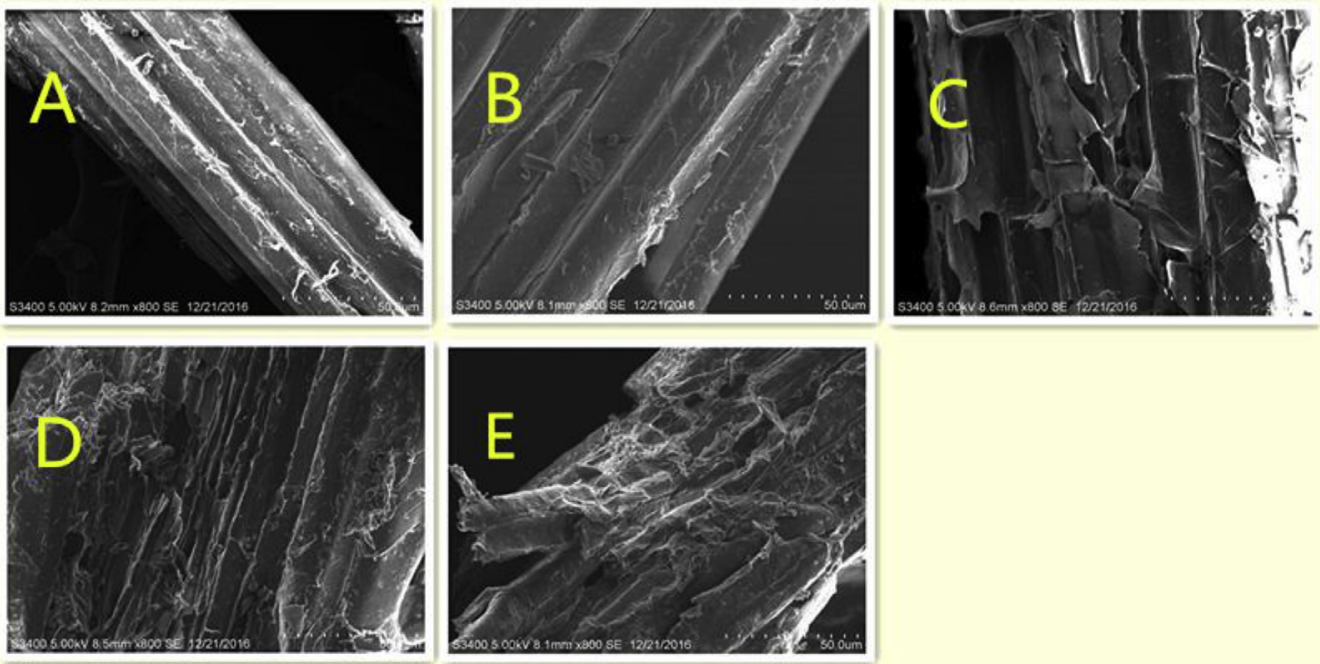

Fig. 1 - SEM images of different samples (A) raw, (B) after HTP, (C) after HCl-P, (D) after $\mathrm{HCl}+\mathrm{U}$ and (E) after $\mathrm{HCl}+\mathrm{M}$. 
Table 1 - Chemical composition and CrI value of before and after pretreatments.

\begin{tabular}{lccccc} 
Pretreatment & \multicolumn{4}{c}{ Composition (\%) } & CrI (\%) \\
\cline { 2 - 5 } & Solid yield & Hemicellulose & Cellulose & Lignin \\
\hline Raw & 100 & 28.38 & 44.48 & 17.60 & 37.50 \\
HTP & 83.50 & 28.34 & 42.23 & 18.42 & 36.60 \\
HCl-P & 69.55 & 18.14 & 45.57 & 16.54 & 39.79 \\
HCl + U & 67.88 & 16.74 & 46.13 & 15.56 & 41.09 \\
HCl + M & 65.72 & 16.53 & 46.95 & 15.09 & 41.50 \\
\hline
\end{tabular}

pretreated TL were conducted by X-ray diffraction (XRD) analysis to illustrate the crystal structural change, and the CrI of samples is listed in Table 1. The CrI of control and after HTP showed no difference, because the HTP was mild, showing insignificant effect, which was similar to that reported by Sun et al. [31]. The CrI after HCl-P was higher than that of the raw, which might be attributed to the main $\mathrm{HCl}$ attack to the amorphous region of cellulose [32,33]. Microwave and ultrasound reinforced the $\mathrm{HCl}-\mathrm{P}$, resulting in an increase of $\mathrm{CrI}$. The obvious increase in crystallinity indicated that dilute acid pretreatment might mainly disrupt the amorphous zone of cellulose, inducing the peak at $2 \theta=22.6^{\circ}$ higher than the control. The CrI increased by $10.67 \%$ as a result of $\mathrm{HCl}+\mathrm{M}$, making the pretreated TL more accessible to enzyme. This finding agreed with the report from Romaní et al. [34].

The main characteristics of FT-IR spectra are assigned to observe functional groups presented in cellulose, hemicellulose, and lignin $[35,36]$. As shown in Fig. 2, when the sample was pretreated, some obvious differences could be observed as expected. Fig. 2 shows several intense bands for hemicellulose or lignin at 1725, 1600, 1505 and $1374 \mathrm{~cm}^{-1}$, and the broad peak at $3200-3500 \mathrm{~cm}^{-1}$ was associated with $\mathrm{O}-\mathrm{H}$ stretching vibration, which was attributed to carbohydrate and aromatic ring. The FT-IR spectrum of control and sample after HTP was similar, which indicated that the mild pretreatment insignificantly changed the functional groups of TL [37]. It could be observed that the intensity of peak at

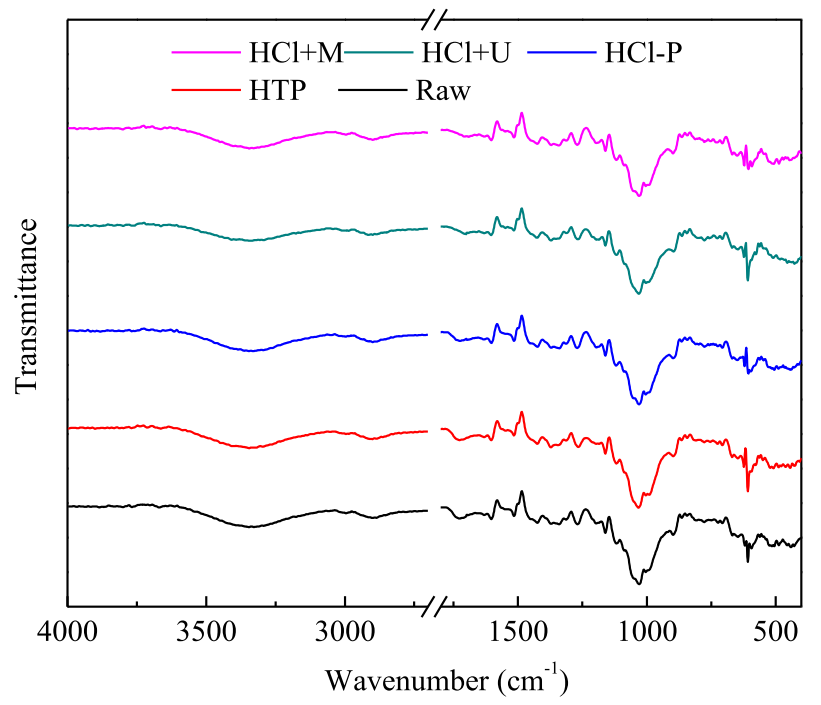

Fig. 2 - FT-IR spectra of samples before and after pretreatments.
$3200-3500 \mathrm{~cm}^{-1}$ reduced, and this region became wide after $\mathrm{HCl}-\mathrm{P}$, which suggested that a certain number of hydroxyl bonds were broken and the structure of cellulose became much looser. It was also found that the characteristic peak at $1725 \mathrm{~cm}^{-1}$ nearly disappeared. This peak was associated with $\mathrm{C}=\mathrm{O}$ (carbonyl) and $\mathrm{C}-\mathrm{O}$ (carbohydrate) stretching vibration. The $\mathrm{C}=\mathrm{O}$ and $\mathrm{C}-\mathrm{O}$ groups were from aromatic skeletal of hemicellulose or lignin, and their peak disappearance indicated the HCl-P removed the hemicellulose and lignin,

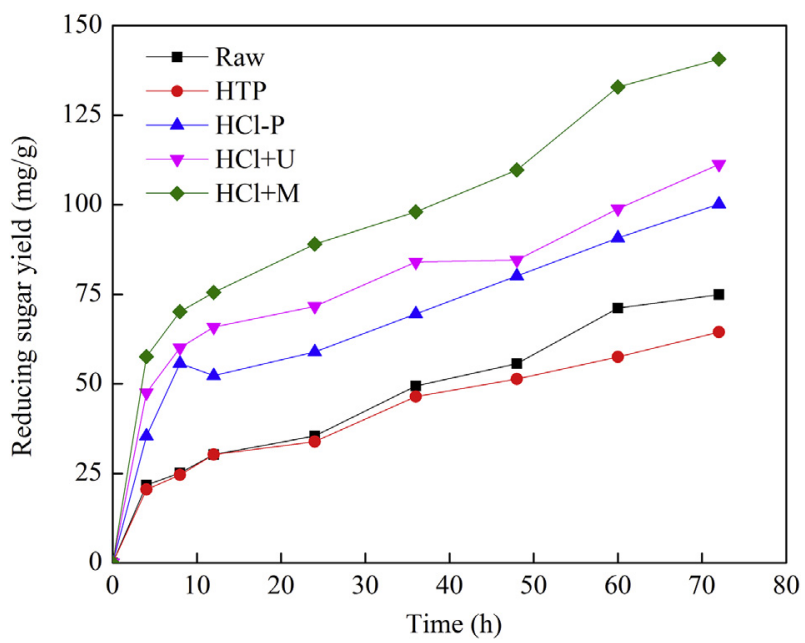

Fig. 3 - Reducing sugar production of TL before and after pretreatments.

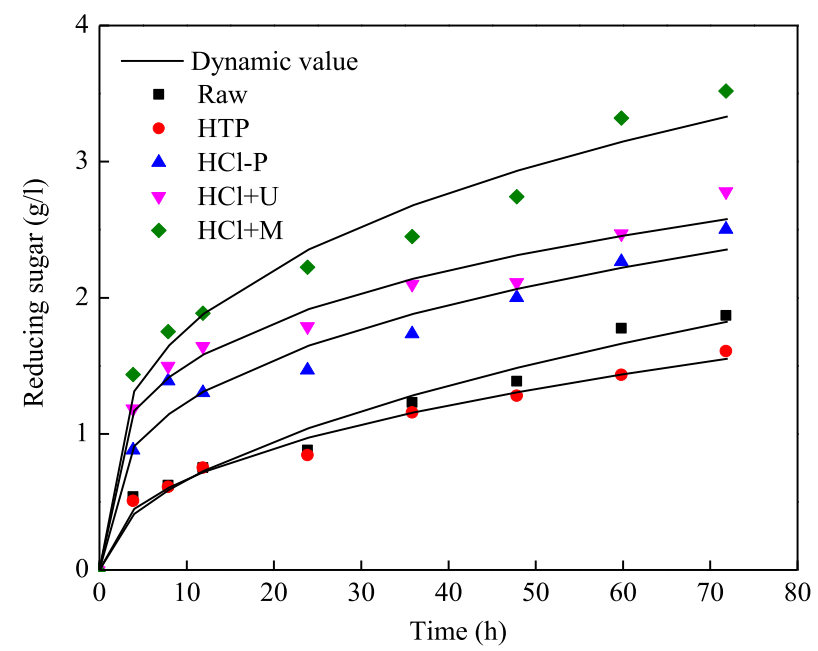

Fig. 4 - Fitted reducing sugar concentration by fractal-like kinetics model. 
Table 2 - Parametric values fitted by fractal-like kinetics model.

\begin{tabular}{lccc} 
Pretreatment & \multicolumn{3}{c}{ Enzymatic hydrolysis } \\
\cline { 2 - 4 } & $k$ & $h$ & $\mathrm{R}^{2}$ \\
\hline Raw & 0.005790 & 0.471463 & 0.9761 \\
$\mathrm{HTP}$ & 0.006144 & 0.559825 & 0.9879 \\
$\mathrm{HCl}-\mathrm{P}$ & 0.012532 & 0.655716 & 0.9693 \\
$\mathrm{HCl}+\mathrm{U}$ & 0.014905 & 0.710745 & 0.9793 \\
$\mathrm{HCl}+\mathrm{M}$ & 0.018370 & 0.655527 & 0.9780
\end{tabular}

corresponding to the results in Table 1. For the $\mathrm{HCl}+\mathrm{U}$ and $\mathrm{HCl}+\mathrm{M}$, there was no significant change compared to the spectrum of sample after $\mathrm{HCl}-\mathrm{P}$, which indicated that ultrasound and microwave irradiation did not significantly change the chemical structure of TL pretreated by dilute acid. The hemicellulose removal led to a great improvement of the interaction between enzyme and TL. The similar results have been obtained for pretreated poplar and corn stover [38].

\section{Effect of pretreatment on enzymatic hydrolysis and reducing} sugar production of TL

The enzymatic hydrolysis of raw and pretreated TL is comparatively shown in Fig. 3. After enzymatic hydrolysis for $72 \mathrm{~h}$, the reducing sugar production only reached 74.90 and $64.44 \mathrm{mg} / \mathrm{g}$ for the raw TL and TL after HTP, respectively. The lower reducing sugar yield after HTP might be caused by the insufficient cellulose dissolution in a relatively low temperature and the integrated lignocellulosic structure [37]. What is more, the lignin might absorb a part of enzyme, which was inconducive to the subsequent enzymatic hydrolysis [39]. After HCl-P, the reducing sugar yield reached $100.14 \mathrm{mg} / \mathrm{g}$, which could be mainly attributed to the reduction of
Table 3 - Correlation of component and enzymatic hydrolysis of TL.

Component Enzymatic hydrolysis

\begin{tabular}{llc}
\cline { 2 - 3 } & \multicolumn{1}{c}{ Equation } & $\mathrm{R}^{2}$ \\
\hline Cellulose & $\mathrm{Y}_{1}=15.33 \mathrm{X}_{1}-592.81$ & 0.8557 \\
Hemicellulose & $\mathrm{Y}_{2}=-4.39 \mathrm{X}_{2}+193.30$ & 0.8054 \\
Lignin & $\mathrm{Y}_{3}=-21.20 \mathrm{X}_{3}+451.04$ & 0.9415 \\
CrI & $\mathrm{Y}_{4}=0.07 \mathrm{X}_{4}-32.56$ & 0.9135 \\
\hline
\end{tabular}

hemicellulose and lignin corresponding to an increase of cellulose exposure and the increase of sample surface area. When Microwave or ultrasound was used to assist the HCl-P, the hemicellulose and lignin content further decreased, especially showing a lowest hemicellulose and lignin content for the $\mathrm{HCl}+\mathrm{M}$. The reducing sugar yield of $\mathrm{HCl}+\mathrm{M}$ was the highest with $140.67 \mathrm{mg} / \mathrm{g}$, which was 1.9 times than that of the raw TL.

To further clarify the kinetics of enzymatic hydrolysis, the reducing sugar production was fitted into fractal-like kinetics models according to Eq. (1) with nonlinear regression (Fig. 4). The values of $k, h$ and correlation coefficients $\left(R^{2}\right)$ are shown in Table 2 . The experimental data was very close to the modeled curves, and the $\mathrm{R}^{2} 3$ were all above 0.96 , which indicated that the fractal-like theory was suitable for studying the cellulose enzymatic hydrolysis kinetics [25]. The larger the rate constant, the greater the binding capacity between substrates and enzymes [40]. After $\mathrm{HCl}-\mathrm{P}$, the rate constant $k$ was obviously higher than that of the control. The rate constant $k$ of $\mathrm{HCl}+\mathrm{U}$ and $\mathrm{HCl}+\mathrm{M}$ was higher than that of $\mathrm{HCl}-\mathrm{P}$. The probable reason might be that the $\mathrm{HCl}+\mathrm{M}$ was able to greatly remove hemicellulose and efficiently improve the access of enzyme, comparing to other pretreatments.

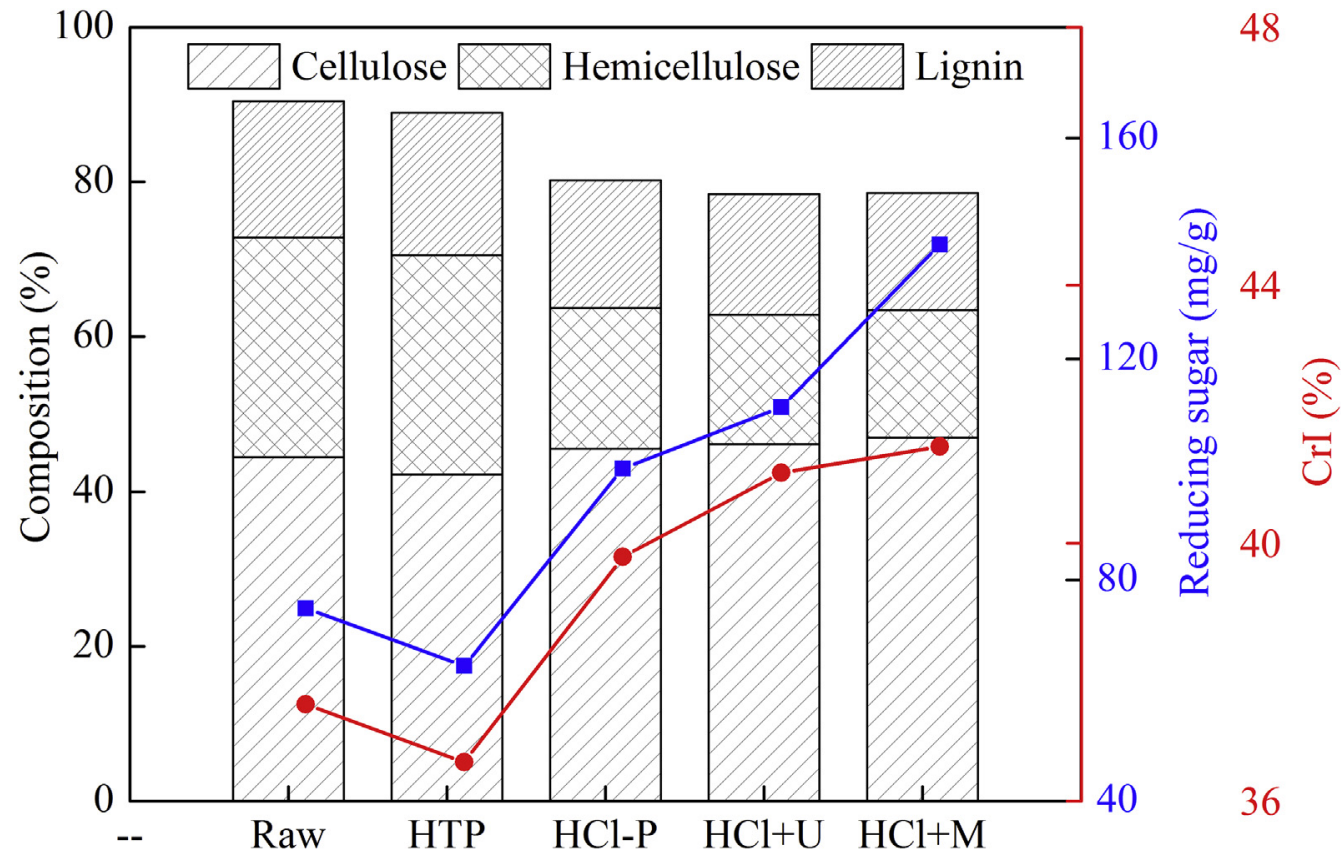

Fig. 5 - Relationship between component and enzymatic hydrolysis of TL. 


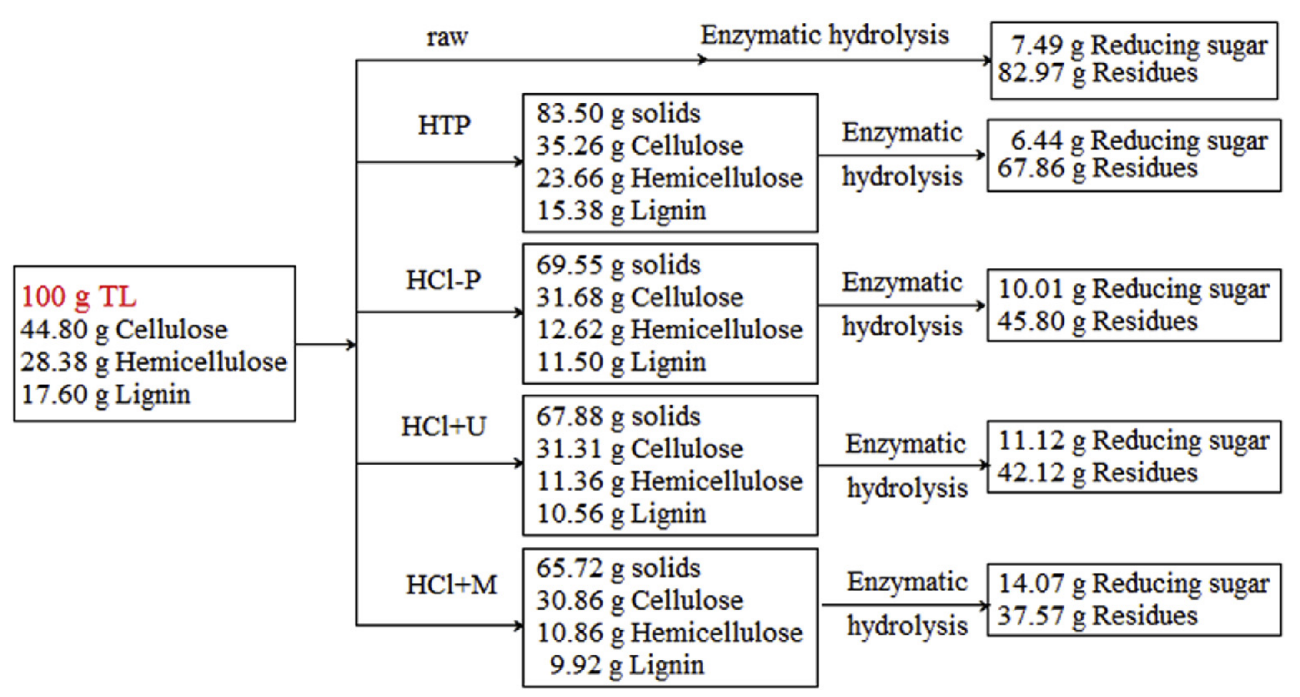

Fig. 6 - Schematic illustration and mass balance for pretreatment and enzymatic hydrolysis based on $100 \mathrm{~g}$ TL.

To deeply understand the effect of chemical component change of TL on the enzymatic hydrolysis, the relationship between the enzymatic digestibility and component change was studied. After pretreatments, the enzymatic hydrolysis was mostly influenced by the content of cellulose and lignin as shown in Fig. 5 and Table 3. The cellulose content showed a positive correlation with the enzymatic hydrolysis, while the hemicellulose and lignin had a negative correlation with the enzymatic hydrolysis. The increase of hemicellulose and lignin removal helped accelerate enzymatic hydrolysis of cellulose and produce more reducing sugar. This is similar to the finding in previous study [8].

The relationship between the CrI and enzymatic hydrolysis has been extensively investigated [41]. The CrI was positively related to enzymatic hydrolysis and the $R^{2}$ reached 0.9135 , which might resulted from the disruption of amorphous cellulose after pretreatments (Fig. 5 and Table 3).

\section{Schematic illustration and mass balance}

Fig. 6 presents a clear schematic illustration and an overall mass balance based on $100 \mathrm{~g}$ raw TL and provides an overview of complete process of pretreatment and enzymatic hydrolysis. The raw TL consisted of $44.80 \mathrm{~g}$ cellulose, $28.38 \mathrm{~g}$ hemicellulose and $17.60 \mathrm{~g}$ lignin, respectively. After different pretreatments the composition of cellulose, hemicellulose and lignin ranged 30.86-35.25 g, 10.86-23.66 g and 9.92-15.38 g, respectively.

After pretreatments, the TL was subsequently enzymatically hydrolyzed at $50^{\circ} \mathrm{C}$ for $72 \mathrm{~h}$ with a cellulase loading of $30 \mathrm{FPU} / \mathrm{g}$. The direct enzymatic hydrolysis of raw TL generated $7.49 \mathrm{~g}$ reducing sugar, and After HTP, $\mathrm{HCl}-\mathrm{P}, \mathrm{HCl}+\mathrm{U}$ and $\mathrm{HCl}+\mathrm{M}$ the reducing sugar was $6.44,10.01,11.12$ and $14.07 \mathrm{~g}$, respectively. The maximum reducing sugar yield of $14.07 \mathrm{~g} /$ 100 g raw TL was achieved after $\mathrm{HCl}+\mathrm{M}$, which indicated that the biorefinery process based on $\mathrm{HCl}+\mathrm{M}$ for TL utilization is promising in the future.

\section{Conclusions}

This research compared four pretreatments, HTP, HCl-P, $\mathrm{HCl}+\mathrm{U}$ and $\mathrm{HCl}+\mathrm{M}$ for enhancing the enzymatic hydrolysis of TL. HCl-P was very effective in solubilizing the hemicellulose and lignin, changing the cellulose structure and further improving enzymatic hydrolysis. After $72 \mathrm{~h}$ enzymatic hydrolysis, the reducing sugar yield reached $100.14 \mathrm{mg} / \mathrm{g}$, increasing by $34 \%$ compared with that of the control. Microwave and ultrasound assistance further improved the enzymatic hydrolysis efficiency of TL, especially the $\mathrm{HCl}+\mathrm{M}$. The results of fractal-like kinetics model showed that $\mathrm{HCl}+\mathrm{M}$ pretreatment is more advantageous for acceleration and improvement of enzymatic hydrolysis of TL. Above all, microwave assisted $\mathrm{HCl}$ pretreatment is the most suitable for improving the bioconversion of TL.

\section{Acknowledgements}

This research was funded by National Natural Science Foundation of China (51578068) and the Specialized Research Fund for the Doctoral Program of Higher Education of China (20130161110013).

\section{R E F E R E N C E S}

[1] York R. Do alternative energy sources displace fossil fuels? Nat Clim Change 2012;2:441-3.

[2] Jin S-G, Zhang G-M, Zhang P-Y, Jin L-Y, Fan S-Y, Li F. Comparative study of high-pressure homogenization and alkaline-heat pretreatments for enhancing enzymatic hydrolysis and biogas production of grass clipping. Int Biodeterior Biodegrad 2015;104:477-81. 
[3] Li H, Fang Z, Smith RL, Yang S. Efficient valorization of biomass to biofuels with bifunctional solid catalytic materials. Prog Energy Combust Sci 2016;55:98-194.

[4] Zhu J-Y, Zhuang X-S. Conceptual net energy output for biofuel production from lignocellulosic biomass through biorefining. Prog Energy Combust Sci 2012;38:583-98.

[5] Fedenko JR, Erickson JE, Woodard KR, Sollenberger LE, Vendramini JMB, Gilbert RA. Biomass production and composition of perennial grasses grown for bioenergy in a subtropical climate across Florida, USA. BioEnergy Res 2013;3:1082-93.

[6] Wang W-X, Zhu Y-S, Du J, Yang Y-Q Jin Y-C. Influence of lignin addition on the enzymatic digestibility of pretreated lignocellulosic biomasses. Bioresour Technol 2015;181:7-12.

[7] Liang Y-G, Zheng Z, Luo X-Z, Si Y-B, Cao D-J, Nie E, et al. Lime pretreatment to improve methane production of smooth cordgrass (Spartina alterniflora). Chem Eng J 2013;217:337-44.

[8] Moretti M, Perrone OM, Nunes C, Taboga SO, Boscolo M, Da Silva R, et al. Effect of pretreatment and enzymatic hydrolysis on the physical-chemical composition and morphologic structure of sugarcane bagasse and sugarcane straw. Bioresour Technol 2016;219:773-7.

[9] Liu Y-Y, Xu J-L, Zhang Y, Liang C-Y, He M-C, Yuan Z-H, et al. Reinforced alkali-pretreatment for enhancing enzymatic hydrolysis of sugarcane bagasse. Fuel Process Technol 2016;143:1-6.

[10] Perrone OM, Rossi JS, Moretti M, Nunes C, Bordignon SE, Gomes E, et al. Influence of ozonolysis time during sugarcane pretreatment: effects on the fiber and enzymatic saccharification. Bioresour Technol 2017;224:733-7.

[11] Tian C-Y, Li B-M, Liu Z-D, Zhang Y-H, Lu H-F. Hydrothermal liquefaction for algal biorefinery: a critical review. Renew Sustain Energy Rev 2014;38:933-50.

[12] Tye YY, Lee KT, Wan Abdullah WN, Leh CP. Optimization of various pretreatments condition of kenaf core (Hibiscus cannabinus) fibre for sugar production: effect of chemical compositions of pretreated fibre on enzymatic hydrolysability. Renew Energy 2016;99:205-15.

[13] Yang Z-M, Guo R-B, Xu X-H, Fan X-L, Li X-P. Enhanced hydrogen production from lipid-extracted microalgal biomass residues through pretreatment. Int J Hydrogen Energy 2010;18:9618-23.

[14] Li K-N, Wan J-M, Wang X, Wang J-F, Zhang J-H. Comparison of dilute acid and alkali pretreatments in production of fermentable sugars from bamboo: effect of Tween 80. Ind Crops Prod 2016;83:414-22.

[15] Noparat P, Prasertsan P, O-Thong S, Pan X. Dilute acid pretreatment of oil palm trunk biomass at high temperature for enzymatic hydrolysis. Energy Procedia 2015;79:924-9.

[16] Chen W-H, Ye S-C, Sheen H-K. Hydrolysis characteristics of sugarcane bagasse pretreated by dilute acid solution in a microwave irradiation environment. Appl Energy 2012;93:237-44.

[17] Zhou X. Dilute sulfuric acid pretreatment of geneticallyengineered switchgrass for improved sugar production. Bioresour Technol 2011;104:823-7.

[18] Balat M, Balat H, Öz C. Progress in bioethanol processing. Prog Energy Combust Sci 2008;34:551-73.

[19] Passos F, Carretero J, Ferrer I. Comparing pretreatment methods for improving microalgae anaerobic digestion: thermal, hydrothermal, microwave and ultrasound. Chem Eng J 2015;279:667-72.

[20] Yu Z-L, Zeng W-C, Zhang W-H, Liao X-P, Shi B. Effect of ultrasonic pretreatment on kinetics of gelatin hydrolysis by collagenase and its mechanism. Ultrason Sonochem 2016;29:495-501.

[21] Zhou X-Q, Zhao J-Y, Li Z-F, Song J-N, Li X-Y, Yang X, et al. Enhancement effects of ultrasound on secondary wastewater effluent disinfection by sodium hypochlorite and disinfection by-products analysis. Ultrason Sonochem 2016;29:60-6.

[22] Cheng J, Su H-B, Zhou J-H, Song W-L, Cen K-F. Microwaveassisted alkali pretreatment of rice straw to promote enzymatic hydrolysis and hydrogen production in dark- and photo-fermentation. Int J Hydrogen Energy 2011;3:2093-101.

[23] Singh R, Tiwari S, Srivastava M, Shukla A. Performance study of combined microwave and acid pretreatment method for enhancing enzymatic digestibility of rice straw for bioethanol production. Plant Knowl J 2013;4:157-62.

[24] Singh R, Tiwari S, Srivastava M, Shukla A. Microwave assisted alkali pretreatment of rice straw for enhancing enzymatic digestibility. J Energy 2014;3:1-7.

[25] Zhang Y, Xu J-L, Qi W, Yuan Z-H, Zhuang X-S, Liu Y, et al. A fractal-like kinetic equation to investigate temperature effect on cellulose hydrolysis by free and immobilized cellulase. Appl Biochem Biotechnol 2012;168:144-53.

[26] Segal L, Creely JJ, Martin AE, Conrad CM. An empirical method for estimating the degree of crystallinity of native cellulose using the X-ray diffractometer. Text Res J 1959;29:786-94.

[27] Zhang L-M, You T-T, Zhou T, Zhang L, Xu F. Synergistic effect of white-rot fungi and alkaline pretreatments for improving enzymatic hydrolysis of poplar wood. Ind Crops Prod 2016;86:155-62.

[28] Diaz AB, Moretti M, Bezerra-Bussoli C, Carreira Nunes C, Blandino A, Da Silva R, et al. Evaluation of microwaveassisted pretreatment of lignocellulosic biomass immersed in alkaline glycerol for fermentable sugars production. Bioresour Technol 2015;185:316-23.

[29] Uluko H, Zhang S, Liu L, Tsakama M, Lu J, Lv J. Effects of thermal, microwave, and ultrasound pretreatments on antioxidative capacity of enzymatic milk protein concentrate hydrolysates. J Funct Foods 2015;18:1138-46.

[30] Zhou B, Zhang M, Fang Z-X, Liu Y. Effects of ultrasound and microwave pretreatments on the ultrafiltration desalination of salted duck egg white protein. Food Bioprod Process 2015;96:306-13.

[31] Sun S-L, Sun S-N, Wen J-L, Zhang X-M, Peng F, Sun R-C. Assessment of integrated process based on hydrothermal and alkaline treatments for enzymatic saccharification of sweet sorghum stems. Bioresour Technol 2014;175:473-9.

[32] Bhagia S, Kumar R, Wyman CE. Effects of dilute acid and flowthrough pretreatments and BSA supplementation on enzymatic deconstruction of poplar by cellulase and xylanase. Carbohydr Polym 2017;157:1940-8.

[33] Gonzales RR, Sivagurunathan P, Kim S. Effect of severity on dilute acid pretreatment of lignocellulosic biomass and the following hydrogen fermentation. Int J Hydrogen Energy 2016;41:21678-84.

[34] Romaní A, Tomaz PD, Garrote G, Teixeira JA, Domingues L. Combined alkali and hydrothermal pretreatments for oat straw valorization within a biorefinery concept. Bioresour Technol 2016;220:323-32.

[35] Liu W-N, Hou Y-C, Wu W-Z, Niu M-G, Wang W-H. Pretreatment of wheat straw using $\mathrm{SO}_{2}$ dissolved in hot water. Bioresour Technol 2012;124:306-10.

[36] Sukhbaatar B, Hassan EB, Kim M, Steele P, Ingram L. Optimization of hot-compressed water pretreatment of bagasse and characterization of extracted hemicellulose. Carbohydr Polym 2014;101:196-202.

[37] Sun S-L, Wen J-L, Ma M-G, Sun R-C. Enhanced enzymatic digestibility of bamboo by a combined system of multiple steam explosion and alkaline treatments. Appl Energy 2014;136:519-26.

[38] Kumar R, Mago G, Balan V, Wyman CE. Physical and chemical characterizations of corn stover and poplar solids 
resulting from leading pretreatment technologies. Bioresour Technol 2009;17:3948-62.

[39] Zheng Y-F, Zhang S-P, Miao S-D, Su Z-G, Ping W.

Temperature sensitivity of cellulase adsorption on lignin and its impact on enzymatic hydrolysis of lignocellulosic biomass. J Biotechnol 2013;166:135-43.
[40] Väljamäe P, Kipper K, Pettersson G, Johansson G. Synergistic cellulose hydrolysis can be described in terms of fractal-like kinetics. Biotechnol Bioeng 2003;84:254-7.

[41] Zhu L, O Dwyer JP, Chang VS, Granda CB, Holtzapple MT. Structural features affecting biomass enzymatic digestibility. Bioresour Technol 2008;99:3817-28. 